\title{
Teaching of neuroanatomy by means of self-instructional laboratory stations
}

\author{
L. J. FISHER, W. K. DAVIS, ELIZABETH J. HITCH AND PATRICIA A. BARR \\ The University of Michigan Medical School and Office of Educational Resources and Research, University of Michigan, \\ Ann Arbor, Michigan U.S.A.
}

\begin{abstract}
Summary
Neuroanatomical Iaboratory material was presented to first-year medical students in a series of six self-instructional stations. Each station was designed to emphasize one major objective and to be completed without reference to any other station. Upon completion of a station the students filled out a response questionnaire. Five weeks later, short examinations testing both station content and application of the neuroanatomical principles were administered to volunteers from the class.

Student response to this teaching format was highly favourable for all areas questioned. Results of the tests indicated a mastery of station material as defined by the objectives and an ability to use the material in applied problems. The laboratory station concept is economical of both student and instructor time and allows flexibility in the design of neuroanatomical laboratory experiences.
\end{abstract}

Key words: Neuroanatomy/*educ; *Education, MEDICAL, UNDERgRAdUATE; *Teaching Materials; LABORATORIES; TEACHING/methods; Michigan

\section{Introduction}

Neural and Behavioral Sciences at the University of Michigan Medical School is a four-semester course involving neuroanatomy and several other discipplines. As this course evolved, less time was allotted

Correspondence: Leslie J. Fisher, Assistant Professor of Anatomy, 5713 Medical Science II, The University of Michigan Medical School, Ann Arbor, Michigan 48109, U.S.A.

0308-0110/80/0300-0119\$02.00 (C)1980 Medical Education for laboratory sessions in neuroanatomy chiefly because fewer instructors were available. In addition, to improve instructor efficiency, an increased emphasis was placed upon the lecture format. The decline in the use of the laboratory as a teaching technique was felt to be undesirable in the education of medical students. Accordingly, a system was developed which presents actual specimen materials in a format which retains the immediacy of the traditional laboratory and yet is more economical of the time of both students and instructors. The basis of this system is a series of self-instructional stations which use laboratory material as an integral part of the teaching-learning process.

Studies evaluating the effectiveness of selfinstructional teaching techniques have stressed the use of alternatives to specimen material. Stereo slides were used in place of gross dissection (Kahn, Conklin \& Glover, 1973); microfiche replaced microscopic slides (Prentice et al., 1977); or audiovisual materials replaced laboratory experiences (Metcalf \& Moffatt, 1972). The laboratory station approach described in this article contrasts with the above examples by retaining specimen material and incorporating it into the teaching programme. Discovery, feedback, and reinforcement are provided by the specimen as well as the written material. This approach retains the direct experiences of a laboratory but additionally introduces the power of guided, self-instructional techniques.

\section{Methods}

To implement and test the effectiveness of this concept six laboratory stations were developed each of which covered a specific topic in neuroanatomy. Instructional objectives were stated for each station 
and an organized sequence of explanations, examples, manipulations, questions and answers was conceived to fulfil the objectives. In addition to designing experiences which would achieve the instructional objectives, several criteria were imposed which governed the more mechanical aspects of station design. Packaging, time to completion, accessibility and station format all presented limitations to be considered. The result of this process was a series of compatible stations which are consistent in overall format and yet different in the specific tasks required of the student.

Two facets of the laboratory stations were evaluated: (1) effectiveness of presentation for content mastery and (2) acceptance of this form of laboratory approach by the students. To evaluate the effectiveness of the stations, examinations were prepared which measured the achievement of the stated objectives. To assess student acceptance, questionnaires probed the students reactions to the method of presentation.

Only three stations were selected for this evaluation since the tests were not to be used for grading purposes and examination time had to be extracted from laboratory time. The results of the evaluations of these stations are considered to indicate the general quality of all stations.

For each of the three stations, a twenty-question examination was constructed. Ten of the questions assessed the stated objectives of that station and ten questions assessed the student's ability to apply the neuroanatomical principles to clinically relevant situations. The examinations were administered to volunteers from the first-year medical student class 5 weeks after completion of the station.

\section{Design and implementation}

For the laboratory stations to be effectively implemented, their design had to be responsive to the limitations and objectives of the subject matter to be taught, and to a teaching situation with a studentto-teacher ratio as high as 100 to 1 . Consequently, each laboratory station is limited to few concepts, is able to be completed within 20 minutes, requires no other station as a prerequisite, and utilizes specially prepared specimen material as an integral part of the teaching-learning programme. The topics of the six stations developed for this study are: (1) Horizontal Brain Slice, (2) Internal Structures of the Forebrain in Horizontal Section, (3) Ventricular
Sytem, (4) Cranial Nerves, (5) Areas of the Brainstem, and (6) Lobes of the Forebrain: Lateral Surface.

Each of these stations uses a different technique to introduce the material and yet each station is packaged and presented in the same format. For example, in Lobes of the Forebrain: Lateral Surface, the student first identifies the boundaries of the several lobes, and then identifies features on the brain, verifying their identification by referring to numbered pins on the specimen. In this manner the student learns the features which identify the lobes and develops a sense of scale and orientation on the actual brain. In the Cranial Nerves station, on the other hand, the student is required to identify the cranial nerves on a rubber model and then on a real brainstem. After identification, a series of tables are completed on which the student lists location, name, and function of the cranial nerves.

Each station clearly states purpose and objectives followed by a summary of prerequisite information necessary for completing the station. Next, directions are given for the performance of the station. These include procedural instructions along with informational material. A sample of the format of one station, Areas of the Brainstem, is given in Figs 1a1d. An instructor's guide sheet (Fig. 1a) gives the materials needed for the station and outlines all setup procedures. The instruction sheet (Fig. 1b) tells the student how to proceed and the answer sheets (Figs. 1c and 1d) provide corrective feedback.

In order to accommodate as many as 200 students in a single laboratory session, the stations are designed to be performed in any order and to take approximately the same length of time to complete. Six replicates of each station are provided thus allowing all 200 students to use the stations simultaneously.

\section{Results}

Student response to this teaching format was favourable (Fig. 2). More than $98 \%$ of the students responding found the stations interesting, well organized, and clearly written with teaching techniques appropriately matched to the topic. In some station replicates a self-quiz was included. Ninetynine percent of the respondents felt that the quiz was a valuable addition to the station. Ninety per cent $(n=181)$ indicated that the level of difficulty of the stations was appropriate for their degree of 


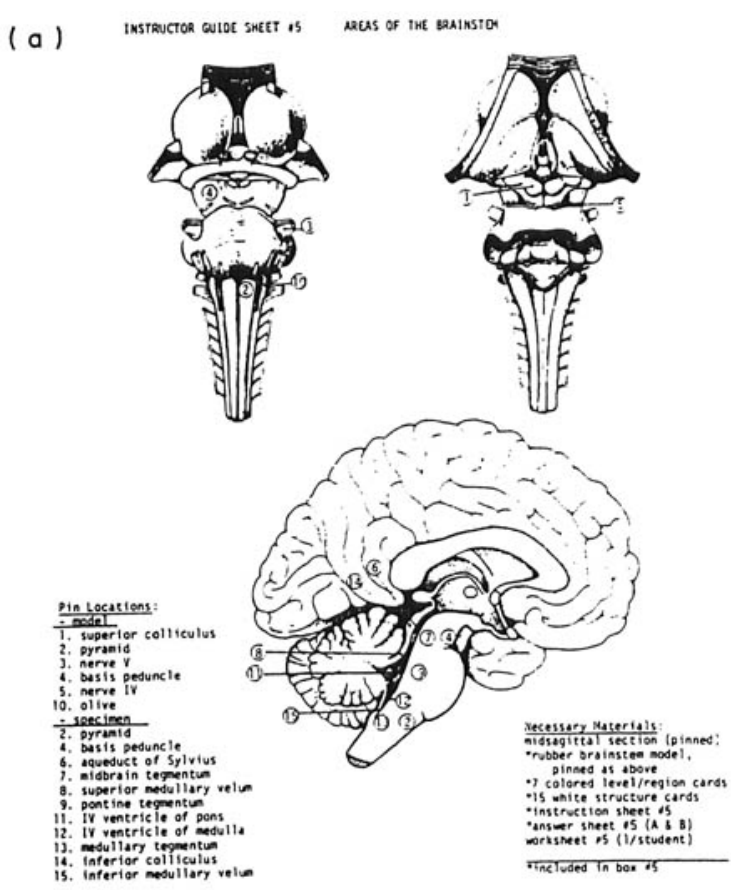

(c)

MSWER SHEET OS (A) AREAS OF THE BRAINSTEM
INSTRUCTION SHEET IS AREAS OF THE BRAINSTEM

\section{Prerequisite Skills:}

An introduction to the structure of the brainstem

Purpose:

To locate specific brainstem structures by identifying the region (midbrain, pons, or medulla) and the area within each regton (roof.
ventricle, tegmentum or base) to which these structures belong.

\section{objectives:}

Given a rubber brainstem model and a midsagittal section of a human brain,

1. Identify the levels of the brainstem: midbrain, pons, and medulla.

2. Identify the ventral to dorsal regions of the brainstem: roof, ventricular space, tegmentum (core), base.

Instructions:

1. On worksheet 15 , note the three levels of the brainstem. Locate the three levels (midbrain, pons, medulla) on the rubber brainstem model and label the diagram.

2. Fol low the same procedure as in instruction above with the four dorsal to ventral regians of the brainstem [roof, ventricular space. tegmentum (core), and base)

3. Check and correct your labels using answer sheet is (A).

4. Arrange the colored cards in a matrix with the three levels on the left and the four dorsal to ventral regions at the top.

5. The numbers on the white structure cards correspond to the numbered pins on both the miodel and the specimen. Using the information from the models, specimen, and cards, divide the cards into four piles: roof structures, ventricular spaces, tegmental structures, basal structures. Place
level of the brainstem.

6. Check your answers on answer sheet 15 (B).

7. Now fill in the spaces on worksheet 15 co correspond to the card matrix you've bullt. Keep your workstheet for future reference.

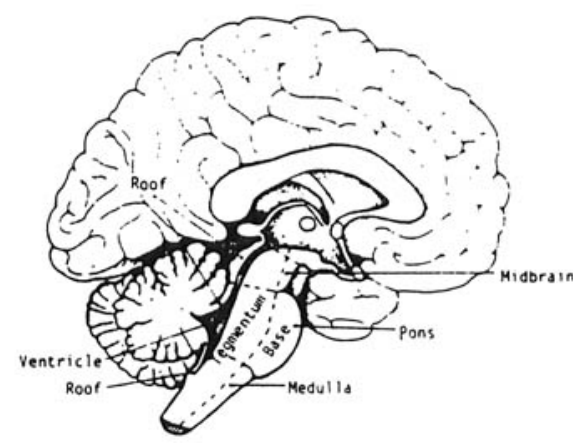

\begin{tabular}{|c|c|c|c|c|}
\hline & ROOF & VENTRICLE & TEGMENTUM & BASE \\
\hline MLOBAa IM & $\begin{array}{l}\text { 1. Superior } \\
\text { colliculus } \\
\text { 5. Merve IV } \\
\text { 14. Inferior } \\
\text { Iollifitus }\end{array}$ & $\begin{array}{l}\text { 6. Aqueduct of } \\
\text { Sylvius }\end{array}$ & $\begin{array}{l}\text { 7. Midbrain } \\
\text { tegmentum }\end{array}$ & $\begin{array}{l}4 . \\
\text { Bosis } \\
\text { peduncle }\end{array}$ \\
\hline PGNS & $\begin{array}{l}\text { 8. Superior } \\
\text { meduluary } \\
\text { velum }\end{array}$ & 11. IV rentercicie & $\begin{array}{l}\text { 9. Pontine } \\
\text { tegmentum }\end{array}$ & 3. Herve \\
\hline MEOULLA & $\begin{array}{l}\text { 15. Inferior } \\
\text { medullary } \\
\text { velum }\end{array}$ & 12. $\begin{array}{l}\text { IV Ventricle } \\
\text { (medulla) }\end{array}$ & $\begin{array}{l}\text { 10. Olive } \\
\text { 13. Medulary } \\
\text { tegmentum }\end{array}$ & $?_{\text {Pyramids }}^{2}$ \\
\hline
\end{tabular}

FIG. 1. Sheets 1a-1d, laminated in plastic, are the basis of the laboratory station entitled Areas of the Brainstem. 1a is an instructor's guide which details the materials necessary for the station; $1 \mathrm{~b}$ is the student instruction sheet; $1 \mathrm{c}$ and $1 \mathrm{~d}$ are answer sheets. Also included in this station are numbered and labelled cards which must be put into the correct order by the student, and a worksheet which is completed and kept by the student. A mid-sagitally sectioned brain and brainstem model, each with labelled pins appropriately placed are also provided. 


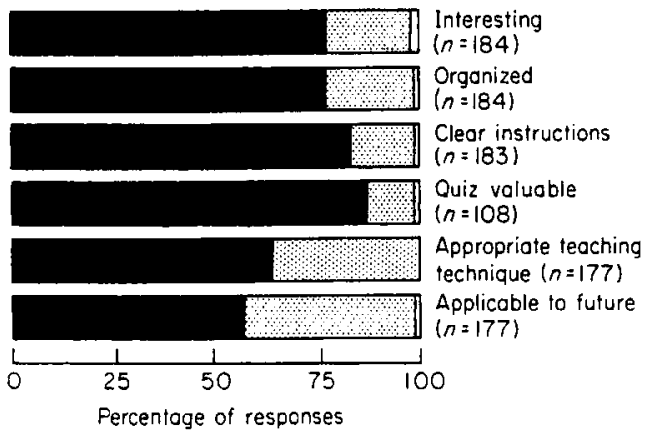

Fig. 2. Student ratings of the laboratory stations. The three stations were rated together on a three choice scale of yes, somewhat, or no for the six statistics listed. Less than $5 \%$ of the students were dissatisfied with these aspects of the technique.

$f$, Percentage of 'yes' responses; $\triangle$ percentage of 'somhewat' responses; $\triangle$, percentage of 'no' responses.

sophistication with $5 \%$ indicating that the material was too easy and $5 \%$ indicating that it was too difficult. Ninety-eight percent $(n=178)$ felt that they were adequately prepared to complete the stations.

Separate tests covering material from three of the stations were administered 5 weeks after the laboratory was completed. The mean score for the combined tests was $88 \%$ correct with the lowest mean for a single station of $81 \%$ correct (Table 1). The mean of the scores on the application questions for each test did not differ significantly from the mean of the scores on the content questions $(P \geqslant$ 0.05 for each test).

Although the laboratory experiences were each designed to be completed in no more than 20 minutes, students reported spending between 7 minutes and 1 hour and 40 minutes per station. The average amount of time spent per station for all six stations was 31 minutes.

Instructor time spent in preparing the laboratory session was found to be much less than required for traditional laboratories. Once the individual stations had been designed and packaged, and the specimen material prepared (before the beginning of the semester), all that remained was to distribute the stations to the rooms in which they were to be used. Subsequent to the initial use of these stations by the first-year medical students, the same stations and specimens were used without further preparation by students in other courses throughout the calender year. In all, the six original stations with six replicates were used by more than 400 students in one year.

One problem in keeping wet specimens usable for prolonged periods of time was overcome by keeping individual dissections or preparations in airtight plastic cake holders. When the brains were covered with wet paper towels and sealed in the cake holders, they remained usable for one full calendar year, serving many students.

Students were allowed access to the stations at times other than the assigned laboratory periods. Many students used the station accessibility to repeat the stations or to review for exams. This feature proved to be quite popular. Approximately $50 \%$ of the medical class used at least one station more than once over the semester.

\section{Discussion}

Acceptance of these laboratory stations by the students was enthusiatic. Two features might have enhanced this response: (1) using the stations provided a change from the large-class lecture and (2) working with real human brain specimens was novel and exciting. Along with acceptance, of the station format, there was a positive student attitude with respect to the subject matter. The well-defined objectives combined with the teaching instructions

TABLE 1. Results of tests administered 5 weeks after completion of the laboratory stations. The first ten questions tested the students' retention of the station content as defined by the station objectives; the second ten questions tested the students' ability to apply the neuroanatomical principles to clinically relevant problems. Figures are means \pm 1 s.d. and, in parentheses, percentages of questions answered correctly.

\begin{tabular}{lcccc}
\hline Station & $n$ & $\begin{array}{c}\text { Mean score } \\
\text { (1st ten questions) } \\
\text { content }\end{array}$ & $\begin{array}{c}\text { Mean score } \\
\text { (2nd ten questions) } \\
\text { application }\end{array}$ & Total mean score \\
\hline 1 & 26 & $8.96 \pm 1.28(90)$ & $9 \cdot 12 \pm 1 \cdot 31(91)$ & $18.08 \pm 2.43(90)$ \\
2 & 33 & $8.43 \pm 1.52(84)$ & $7.85 \pm 1.28(79)$ & $16.27 \pm 2.00(81)$ \\
3 & 15 & $9.60 \pm 0.74(96)$ & $8.60 \pm 1.64(86)$ & $18.20 \pm 2.01(91)$ \\
\hline
\end{tabular}


and specimen material to give the students an insight into anatomical scale and anatomical relationships in a short time.

It must be stressed that these stations were not merely prosections viewed while reading a prepared text. The technique incorporates the specimen itself into the learning experience by requiring the student to use the material in formulating an answer to a question or performing a step in the instructions. This feature is the key to the laboratory station concept.

From the instructor's standpoint these stations provide at least three advantages once they have been designed, tested, and packaged: (1) graduate students can prepare the specimen materials well in advance of the laboratory date, (2) non-professional personnel can distribute the prepared materials on the laboratory day, and (3) the instructor can consolidate concepts or introduce more advanced material during discussions stimulated by the subject matter.

Test results indicate that the stated objectives were satisfactorily met. During the 2-hour laboratory session each student visited six different stations. Thus, even though the objectives of an individual station were limited, many important concepts were introduced in one laboratory period.

A library of laboratory stations is currently being assembled. With these off-the-shelf packages available, individually designed laboratory sessions will be possible by choosing sets of stations which correlate with course content. Implementation of the laboratory station approach has allowed the Neural and Behavioural Sciences course at the University of Michigan Medical School to retain neuroanatomical laboratories in the curriculum.

\section{Acknowledgments}

We thank Dr Sarah S. Winans and Dr Peter Coyle for their encouragement and helpful suggestions during the development of the laboratory station concept. We appreciate the cooperation of Dr James Taren and the Neural Behavioral Science course at the University of Michigan in the implementation and testing of the stations. This project was funded in part by a grant to the senior author from the Center for Research on Learning and Teaching, and by the Office of Educational Resources and Research, the University of Michigan.

\section{References}

KahN, R.H., Conklin, J.L. \& Glover, R.A. (1973) A selfinstructional program in microscopic anatomy. Journal of Medical Education, 48, 859.

MetCalf, W.K. \& MofFatT, D.J.A. (1973) Learning student center in gross anatomy. Anatomical Record, 172, 440.

Prentice, E.D., Metcalf, W.K., QuinN, T.H., SharP, J.G., JENSEN, R.H. \& Holyoke, E.A. (1977) Stereoscopic anatomy: evaluation of a new teaching system in human gross anatomy. Journal of Medical Education, 52, 758. 